\title{
Devolatilisation kinetics and pyrolytic analyses of Tectona grandis (teak)
}

\author{
A.O. Balogun ${ }^{a}$, O.A. Lasode ${ }^{\text {b,* }}$, A.G. McDonald ${ }^{a}$ \\ ${ }^{a}$ Department of Forest, Rangeland and Fire Science, University of Idaho, Moscow, ID 83844-1132, USA \\ ${ }^{\mathrm{b}}$ Department of Mechanical Engineering, Faculty of Engineering and Technology, University of Ilorin, Ilorin, Nigeria
}

\section{H I G H L I G H T S}

- Devolatilisation kinetics and analytical Py-GC/MS were conducted on Nigerian teak.

- Low ash $(<1 \%)$ and $\mathrm{N}(<1 \%)$ contents and relatively high HHV $(19.8 \mathrm{MJ} / \mathrm{kg})$ for teak was found.

- Variation in $E$ between 222 and $300 \mathrm{~kJ} / \mathrm{mol}$ as a function of $\alpha$ was observed.

- More than one-third of the chemical constituents were phenolic organic compounds.

\section{A R T I C L E I N F O}

\section{Article history:}

Received 19 November 2013

Received in revised form 1 January 2014

Accepted 4 January 2014

Available online 13 January 2014

\section{Keywords:}

Thermogravimetric analysis

Teak

Biomass

Devolatilisation kinetics

Analytical pyrolysis

\begin{abstract}
A B S T R A C T
Devolatilisation kinetics and pyrolytic analyses were carried out on Tectona grandis (teak) using isoconversional methods (Flynn-Wall-Ozawa and Starink) and analytical Py-GC/MS technique respectively. Proximate and elemental analyses were also performed and they showed that the ash and C contents and the HHV were $0.7 \%, 49.6 \%$ and $19.8 \mathrm{MJ} / \mathrm{kg}$ respectively. Biomass sample was subjected to multiple heating rates $(5-35 \mathrm{~K} / \mathrm{min})$ in thermogravimetric experiments and kinetic parameters were evaluated from the non-isothermal TGA curves. The activation energy $(E)$ varied between 222 and $300 \mathrm{~kJ} / \mathrm{mol}$ as a function of degree of conversion. Similarly, the pre-exponential frequency factor $(A)$ varied between $9.6 \times 10^{17}$ and $9.55 \times 10^{24} \mathrm{~min}^{-1}$. Analytical Py-GC/MS showed the presence of $\mathrm{CO}_{2}$, acetic acid, furan +2 -butanone, levoglucosan, trans-coniferyl alcohol and lignin derivatives. The proportion of phenolic compounds identified was more than one-third with isoeugenol, acetoguaiacone, and 4-vinylguaiacol showing dominance.
\end{abstract}

(c) 2014 Elsevier Ltd. All rights reserved.

\section{Introduction}

Biomass has assumed a pivotal role among several alternative energy resources known to humankind. Globally, biomass cultivation and utilisation for energy and chemical production is being pursued vigorously because of its renewable potentials, sustainability prospects and inherent ability to address some environmental concerns engendered by fossil fuel utilisation. Biomass wastes generation often creates disposal and environmental challenges, which make them an ideal feedstock for bioenergy production (Lasode and Balogun, 2010). Biomass characteristics are significantly influenced by climatic conditions, soil types and soil fertility treatment in their respective environment. It is therefore important to carry out a basic data analysis of regional biomass material for specific applications such as Nigerian teak.

Thermochemical conversion processes such as pyrolysis (promotes fuels and chemical extraction) and gasification (ensures syngas production for power generation) are viable means for the

\footnotetext{
* Corresponding author. Tel.: +234 8066778409; fax: +234 8055647409.

E-mail address: oalasode@yahoo.com (O.A. Lasode).
}

utilisation of biomass residues (Bridgwater, 2003; Sami et al., 2001). A major step in these processes is devolatilisation; the liberation of a wide range of volatile species emerging at different rates. An investigation into reaction kinetics is very useful for understanding the devolatilisation/degradation mechanisms and facilitating the design of devolatilisation processes and the sizing of reactors. The optimisation of operating conditions is important not only for industrial purposes but also for quality control of the product. Thermogravimetric analysis (TGA) has become a veritable tool for the evaluation of kinetic parameters in thermal degradation of materials. Prins et al. (2006) and Damartzis et al. (2011) carried out studies on weight loss kinetics and kinetic study of the pyrolysis of cardoon (a herbaceous plant) via TGA measurements under isothermal and non-isothermal conditions, respectively. The primary advantage of non-isothermal measurement is that a single sample is required throughout the entire temperature range for the TGA experiment. However, the use of multiple heating rates has been recommended so as to improve the accuracy of non-isothermal techniques (White and Catallo, 2011).

The devolatilisation characteristics of biomass decomposition can be deduced from non-isothermal TGA and the first derivative 
TGA (DTG) thermograms. These thermograms are also valuable in observing the influence of varied heating rates, devolatilisation temperature, and volatile matter released during biomass decomposition. In addition, the application of several model-fitting techniques to TGA data helps in the determination of kinetic parameters. A class of such techniques is the model-dependent approach which relies on a preliminary assumption of the devolatilisation model and reaction order (Gai et al., 2013). An accurate prediction of the devolatilisation model is crucial and inevitably necessitates a prior knowledge of a probable reaction scheme. In practice, the activation energy $(E)$ and pre-exponential frequency factor $(A)$ are extrapolated from the model of best fit that was statistically selected among a series of reaction model fitted to nonisothermal data (Zhou and Grant, 2004). This method is error prone; it produces an unreliable outcome with large discrepancies found among the different reaction models (Chen et al., 2006). Additionally, the ideal model adopted fails to truly capture the events often encountered in heterogeneous reactions (Gai et al., 2013; Damartzis et al., 2011).

Suitable alternatives are the iso-conversional methods commonly referred to as model-free techniques. They were originally conceived for single step reactions (Biagini et al., 2008), which would sufficiently capture thermal processes for homogenous materials. However, the thermal decomposition of lignocellulosic biomass often involves cleavage of chemical bonds in the polymeric components following successive and parallel reaction routes. For instance, lignin has been reported to decompose over a wide temperature range (473-773 K) (Wongsiriamnuay and Tippayawong, 2010). The most reactive of biomass fractions, hemicellulose starts decomposition at about $523 \mathrm{~K}$, while cellulose begins at $570 \mathrm{~K}$ and shows a maximum mass loss rate at about $660 \mathrm{~K}$ (Gaur and Reed, 1998). Moreover, the interplay of the consequent chemical transformation (phase transition from solid to liquid to gas) and the physical processes (heat and mass transfer) also introduces complexities into the interpretation of biomass kinetics (Damartzis et al., 2011). Apparently, a more robust model other than a single step will be required to describe biomass decomposition. The following improvements were incorporated into iso-conversional method for a better simulation of multi-step reactions: (1) performance of TGA runs at multiple heating rates and (2) evaluation of $E$ as a function of degree of conversion. The need for an assumption on the devolatilisation model is also eliminated (Gai et al., 2013). The intricacies of multi-step reaction are thus better modelled by iso-conversional techniques providing a valid result for the devolatilisation kinetics.

Lately, the University of Ilorin, Nigeria in an effort to apply the principles of sustainable development to the environment instituted an ambitious programme of planting 100,000 seedlings of teak (Tectona grandis) for a period of five years and it started off with 70,383 seedlings on a 57 hectares of land in 2008 (Oloyede et al., 2009). Teak is also one of the common tree species used as wooden transmission poles and for other structural purposes in Nigeria (Babalola, 2008). Teak harvesting and processing evidently generate significant quantities of residues that can be utilised for thermochemical conversion.

Pyrolysis is one of the thermochemical conversion processes that may be used in harnessing energy potentials of biomass resources. It takes place between 723 and $873 \mathrm{~K}$, essentially for the production of condensed liquid (bio-oil) (Azeez et al., 2010). The chemical composition of the bio-oil is often of particular interest to scientists for its utilisation as biofuels. Analytical pyrolysis gas chromatography/mass spectrometry (Py-GC/MS) is a valuable technique for prospecting the wide spectrum of volatile species that may be found in bio-oil (Greenhalf et al., 2013). Azeez et al. (2010) carried out analytical Py-GC/MS on hardwood, that is, iroko (Chlophora excelsa) of African origin.
Iso-conversional methods have been used extensively for the kinetic study of non-woody biomass such as wheat straw (Cai and Bi, 2009), bagasse, cashew nut shells, palm stems, coffee husks (Wilson et al., 2011), and orange waste (Lopez-Velazquez et al., 2013). There exists, however, limited literature on kinetics of woody biomass resource; particularly of tropical origin. The primary objective of this study therefore was to conduct reaction kinetics using model-free techniques and analytical Py-GC/MS on Teak of Nigerian origin in view of the prospective local production of biofuels from its wastes.

\section{Methods}

\subsection{Materials}

Teak was obtained from a timber processing plant in December 2012 at Ilorin, Nigeria $\left(8^{\circ} 29 \mathrm{~N}, 4^{\circ} 32 \hat{E}\right)$. Wood chips $(15 \times 10 \times 10 \mathrm{~mm})$ from tree lumber, aged between 40 and 45 years were produced. These were packed in polyethylene bags and transported to the Laboratory in the Department of Forest, Rangeland and Fire Science, University of Idaho, Moscow, Idaho, USA. The biomass samples were then ground in a Thomas Wiley Laboratory Mill Model 4, sieved into particles sizes of 0.25$0.5 \mathrm{~mm}$ and stored in Ziploc bags at room temperature.

\subsection{Methods}

\subsubsection{Proximate and elemental analyses, and heating value}

The method according to ASTM D1102-84 was used for the evaluation of the ash content, while the moisture content (MC) measurement was performed on a HB 43-S Mettler Toledo moisture analyzer. The fixed carbon (FC) content was calculated by difference. Elemental analysis was conducted by CE 440 elemental analyzer to determine $\mathrm{C}, \mathrm{H}$ and $\mathrm{N}$ contents and $\mathrm{O}$ was calculated by difference. The Higher heating value (HHV) of biomass samples, in triplicate, was determined using a Parr oxygen bomb calorimeter model 1341 according to ASTM D5865-04.

\subsubsection{Compositional analysis}

Compositional analysis was conducted using both wet chemistry and instrumental analytical methods to obtain the extractive and lignin contents according to ASTM D1108-96 and ASTM D1106-96 respectively.

\subsection{Thermogravimetric analysis (TGA)}

Devolatilisation tests were conducted on a thermogravimetric analyser (Perkin Elmer TGA-7, Massachusetts, USA) with $\mathrm{N}_{2}$ purge gas $(30 \mathrm{~mL} / \mathrm{min}$ ). Samples $(2-5 \mathrm{mg}$ ) were analysed at linear heating rates of $5,15,25$, and $35 \mathrm{~K} / \mathrm{min}$. The experiments were carried out under non-isothermal conditions; temperature was held for $1 \mathrm{~min}$ at $50^{\circ} \mathrm{C}$ and subsequently ramped from 50 to $900{ }^{\circ} \mathrm{C}$. These were done in duplicates and good reproducibility was obtained.

\subsection{Kinetic modelling}

The global kinetic equation for the decomposition rate in solidstate may be expressed as a product of Arrhenius' expression and a function of the extent of conversion

$\frac{d \alpha}{d t}=A \exp ^{\left(-\frac{E}{R T}\right)} f(\alpha)$

where $A$ is the pre-exponential frequency factor $\left(\mathrm{min}^{-1}\right), E$ is the activation energy $(\mathrm{J} / \mathrm{mol}), R$ is the universal gas constant $(8.314 \mathrm{~J} / \mathrm{mol} \mathrm{K}), T$ is the absolute temperature $(\mathrm{K}), \alpha$ is the extent 
of conversion and $f(\alpha)$ is the reaction model which is a function of conversion.

Thermal decomposition of lignocellulosic materials comprise a series of complex reactions involving various chemical constituents occurring simultaneously. This creates a major challenge for adopting a simple kinetic modelling. Model-free techniques are more robust and are conventionally applied for the determination of apparent $E$ and $A$. These rely on a set of thermogravimetric experiments based on multiple heating rates at a particular fraction of conversion. This eliminates the need for a reaction model and 'compensation effect' in the determination of kinetic parameters. They provide relatively accurate results when compared with some other model-fitting techniques (Damartzis et al., 2011). At constant linear heating rate $\beta=d T / d t$, integrating Eq. (1) by separation of variables gives:

$\int_{0}^{\alpha} \frac{d \alpha}{f(\alpha)}=g(\alpha)=\frac{A}{\beta} \int_{T_{0}}^{T} \exp ^{\left(-\frac{E}{R T}\right)} d T$

If $T_{0}$ falls well below the temperature where the rate of decomposition cannot be measured, the lower limit of the integral form vanishes. Let $x=\left(-\frac{E}{R T}\right)$, Eq. (2) becomes

$g(\alpha)=\left(\frac{A E}{\beta R}\right)\left\{-\frac{\exp ^{x}}{x}+\int_{0}^{\infty}\left(\frac{\exp ^{x}}{x}\right) d x\right\}=\left(\frac{A E}{\beta R}\right) p(x)$

The term $p(x)$ symbolises the temperature integral and it does not have an exact analytical solution. The two possible approximations adopted for this study were explained in Sections 2.4.1 and 2.4.2.

\subsubsection{Flynn-Wall-Ozawa's (FWO) method}

The FWO method is one of the notable model-free techniques commonly used for the determination of kinetic parameters. The FWO method linearises the temperature integral in Eq. (3) using Doyle's empirical approximation (Doyle, 1965) as shown in Eq. (4).

$\log p(x) \cong-2.315+0.457 x$

Taking logarithm of Eq. (3) and combining with Eq. (4) gives the FWO expression in Eq. (5).

$\log \beta=\log \frac{A E}{g(\alpha) R}-2.315-0.457 \frac{E}{R T}$

By implication a series of TGA experiments at heating rates $\beta_{1}$, $\beta_{2} \ldots \beta_{i}$ can be conducted and a temperature $T_{j, i}$ at a conversion ratio, $\alpha_{\mathrm{j}}$ and heating rate, $\beta_{i}$, noted. Then a plot of $\log \beta_{i}$ against $T_{j, i}^{-1}$, for each of $j$ conversion ratio, $\alpha_{1}, \alpha_{2} \ldots \alpha_{j}$ will give $j$ iso-conversional lines whose slopes can be calculated from Eq. (6) (Flynn, 1983).

Slope $\cong 0.457 \frac{E}{R}$

Thus, the $E$ at each conversion step can be evaluated from the plot of $\log \beta$ against the reciprocal of absolute temperature. An iterative procedure was used to obtain the final value of Arrhenius $E$ so as to reduce the error introduced by Doyle's approximation (ASTM E1641-07; Flynn, 1983).

\subsubsection{Starink's method}

Starink (1996) examined two iso-conversional techniques (Flynn-Wall-Ozawa and Kissinger-Akhira-Sunose (KAS)) and found out that both conform to the expression in Eq. (7).

$\ln \left(\frac{\beta}{\tau^{s}}\right)=C_{s}-\frac{B E}{R T}$

where for FWO $s=0, B=0.457$ and for KAS $s=2$ and $B=1$. Starink optimised the values for constants $S$ and $B$ and proposed that $s=1.8$, while $B=1.0037$. It was reported that Starink's method was an order of magnitude more accurate than the other two isoconversional methods (Starink, 1996). Hence, Starink's method can be expressed as Eq. (8)

$\ln \left(\frac{\beta}{\tau^{1.8}}\right)=C_{s}-1.0037 \frac{E}{R T}$

A plot of $\ln \left(\frac{\beta}{\tau^{1.8}}\right)$ against reciprocal of absolute temperature gives a straight line of which the slope corresponds to $-1.0037^{\frac{E}{R}}$. The $E$ can thus be calculated from the slope of the graph.

\subsubsection{Evaluation of pre-exponential frequency factor $(A)$}

The evaluation of $A$ was done according to the modified ASTM E1641-07 standard. The $A$ was determined as a function of conversion, and based on the assumption that the decomposition obeys first-order kinetics.

\subsection{Analytical pyrolysis-gas chromatography/mass spectrometry (Py- GC/MS)}

Biomass samples $(<0.1 \mathrm{mg})$ were injected into a quartz capillary tube and pyrolysed at $500{ }^{\circ} \mathrm{C}$ in an inert atmosphere (He, $0.125 \mathrm{MPa}$ ) using Pyrojector II, (SGE Analytical Science) coupled

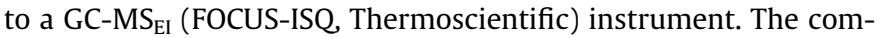
pounds were separated on a RTx-5 ms (30 m $\times 0.25 \mathrm{~mm} \emptyset$, Restek) column with a temperature programme of 50 to $290{ }^{\circ} \mathrm{C}(10 \mathrm{~min})$ at $5^{\circ} \mathrm{C} / \mathrm{min}$. The eluted compounds were identified with authentic standards, NIST 2008 library matching and by their mass spectra (Pillai et al., 2011).

\section{Results and discussion}

\subsection{Biomass characterisation}

Biomass characterisation involves proximate, ultimate, compositional analysis and heating value determination. The proximate analysis gives information on the fixed carbon (FC) and the ash contents, while the elemental analysis provides carbon (C), hydrogen $(\mathrm{H})$, nitrogen $(\mathrm{N})$ and oxygen $(\mathrm{O})$ content determination. The compositional analysis concerns the determination of extractives (Ext), and lignin (Lig) contents. The basic analysis data from this study are compared with results for tropical hardwood from literature as shown in Table 1.

Table 1 shows that the ash content for teak $(<1 \%)$ is much lower than that of iroko (3.5\%), while the C content for teak $(49.6 \%)$ is higher than the value for iroko (43.9\%). It has been demonstrated that low ash and high $\mathrm{C}$ contents contribute significantly to high HHV for lignocellulosic materials (Greenhalf et al., 2013). For iroko and teak respectively, the extractive contents are $8.2 \%$ and $3.5 \%$, while the lignin contents are $26.2 \%$ and $36.5 \%$. Telmo and Lousada (2011) have established through regression analysis that variation in lignin content influences changes in heating value more than extractives. The assertions made above are clearly reflected in the trend portrayed by the characterisation data in Table 1 with teak possessing a comparatively higher HHV than iroko. The values of $\mathrm{N}$ content for both samples are the same $(<1 \%)$; an indication that low emissions of $\mathrm{NO}_{x}$ can be expected if deployed for bioenergy applications.

\subsection{Thermogravimetric analysis (TGA)}

Non-isothermal thermogravimetric experiment conducted at different heating rates is a viable technique for evaluating kinetic parameters of biomass devolatilisation. The application of iso-conversional methods, which are model-free, to non-isothermal data makes this possible. The accuracy achievable is more reliable when 
Table 1

Proximate, ultimate and compositional analyses, and heating values for biomass sample.

\begin{tabular}{|c|c|c|c|c|c|c|c|c|c|}
\hline & \multicolumn{2}{|c|}{ Proximate analysis ${ }^{\mathrm{a}}$ (wt.\%) } & \multicolumn{4}{|c|}{ Elemental analysis ${ }^{\mathrm{a}}$ (wt.\%) } & \multicolumn{2}{|c|}{ Compositional analysis ${ }^{\mathrm{b}}$ (wt.\%) } & \multirow[t]{2}{*}{$\mathrm{HHV}(\mathrm{MJ} / \mathrm{kg})$} \\
\hline & $\mathrm{FC}^{\mathrm{C}}$ & Ash & $\mathrm{C}$ & $\mathrm{H}$ & $\mathrm{N}$ & $\mathrm{O}^{\mathrm{c}}$ & Ext & Lig & \\
\hline Teak & 3.8 & 0.7 & 49.6 & 6.3 & 0.4 & 43.7 & 3.5 & 36.5 & 19.8 \\
\hline Iroko $^{\mathrm{d}}$ & 26.1 & 3.5 & 43.9 & 5.3 & 0.4 & 46.9 & 8.2 & 26.2 & 16.5 \\
\hline
\end{tabular}

a Dry-basis.

b Dry-ash-free.

c Calculated by difference.

d Azeez et al. (2010), HHV = higher heating value.

compared with single dynamic measurements. TGA experiments for thermal decomposition of teak at varied heating rates (5$35 \mathrm{~K} / \mathrm{min}$ ) showed a significant mass loss below $398 \mathrm{~K}$. This early decomposition stage is as a result of moisture evaporation and possibly degradation of light organic compounds. The main devolatilisation stage in teak, a major step in all biomass thermochemical processes, spanned $523-763 \mathrm{~K}$. At this stage, a wide spectrum of volatile species is liberated due to the degradation of the essential polymeric fractions that make up lignocellulosic biomass. There were two distinctive regions. The first region started at less than $538 \mathrm{~K}$, rose sharply to maximum peaks for the respective heating rates and decayed rapidly till around $678 \mathrm{~K}$. The area below $538 \mathrm{~K}$ has been traditionally assigned to hemicellulose decomposition because it is the least stable of the polymeric structure of biomass; thereby decomposing earliest (Burhenne et al., 2013). The maximum DTG peaks for teak at differing heating rates are between 598 and $630 \mathrm{~K}$; these are attributable to cellulose decomposition. Wongsiriamnuay and Tippayawong (2010) observed that cellulose decomposes between 598 and $648 \mathrm{~K}$. The second region (660-778 K) may be indicative of lignin decomposition because it has been noted that lignin degrades over a wider range of temperature (473-773 K) (Wongsiriamnuay and Tippayawong, 2010). Significantly, a further thermal cracking of some resultant organic compounds, whose formation may have been precipitated in the prior primary reactions, could also be responsible. Biagini et al. (2006) in offering an explanation for the weight loss events that succeed primary devolatilisation alluded to the degradation of chemical species that may have been formed during the preceding thermal devolatilisation.

Table 2 shows the influence of heating rate on devolatilisation parameters essentially for the region around the primary peaks. As a preliminary step, some of the terminologies adopted from literature are hereby defined and discussed. $T_{\mathrm{a}}$ and $T_{\mathrm{o}}$ (onset and offset temperature respectively) may be defined as intersections of the tangent to TGA curve (Gaur and Reed, 1998). These variables describe the commencement and ending of the devolatilisation process accordingly. $T_{\max }$ is the temperature at maximum mass loss rate $\left(\mathrm{DTG}_{\max }\right)$, while $\alpha_{\max }$ is the conversion at that temperature. It was observed that as the heating rate increased, all the devolatilisation parameters with the exception of $\alpha_{\max }$, exhibited successive shifts toward higher values. For instance at $5 \mathrm{~K} / \mathrm{min}$,

Table 2

Influence of heating rate on devolatilisation parameters of teak decomposition.

\begin{tabular}{clllll}
\hline Heating rate $(\mathrm{K} / \mathrm{min})$ & $T_{\mathrm{a}}(\mathrm{K})$ & $T_{\mathrm{o}}(\mathrm{K})$ & $T_{\max }(\mathrm{K})$ & $\mathrm{DTG}_{\max }(\% / \min )$ & $\alpha_{\max }(\%)$ \\
\hline 5 & 568 & 620 & 603 & -7.77 & 55 \\
15 & 584 & 627 & 619 & -32.5 & 49 \\
25 & 595 & 639 & 627 & -39.1 & 49 \\
35 & 600 & 645 & 630 & -56.0 & 48
\end{tabular}

$T_{\mathrm{a}}$ (onset temperature) and $T_{\mathrm{o}}$ (offset temperature) are intersections of the tangent to TGA curve. $T_{\max }$ is the temperature at maximum mass loss rate, $\alpha_{\max }$ is the conversion at $T_{\max }$.
$T_{\mathrm{a}}, T_{\mathrm{o}}$ and $T_{\max }$ were respectively at 568,620 and $603 \mathrm{~K}$, while at $35 \mathrm{~K} / \mathrm{min}$ they rose to 600,645 and $630 \mathrm{~K}$. This is in agreement with literature where Biagini et al. (2006) noted that the onset temperature for rice husk devolatilisation at $5 \mathrm{~K} / \mathrm{min}$ was $530 \mathrm{~K}$ and it shifted to $617 \mathrm{~K}$ at $100 \mathrm{~K} / \mathrm{min}$. This may be linked to heat transfer limitations that are usually associated with higher heating rates. A temperature gradient is created between the outer and the inner layers of the sample shifting toward higher temperature as heating rate increases. The increase in value for DTG $_{\max }$ is in consonance with the findings by Damartzis et al. (2011) and Kim et al. (2010) but contrasts with the finding by Biagini et al.

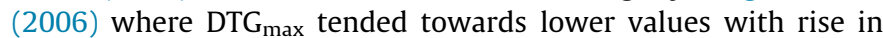
heating rate. Conversion $\left(\alpha_{\max }\right)$ was the highest $(55 \%)$ at $5 \mathrm{~K} / \mathrm{min}$ while it dropped to the lowest value $(48 \%)$ at $35 \mathrm{~K} / \mathrm{min}$. At low heating rates, transfer of heat is facilitated and this encourages mass diffusion that eventually leads to a greater mass loss.

\subsection{Determination of activation parameters based on iso-conversional methods}

The plots of iso-conversional lines in Figs. 1 and 2 were derived from the application of Eqs. (5) and (8) to the TGA data.

The correlation between the logarithmic function containing heating rate and $1 / T$ at $\alpha$ ratios of 0.15 to 0.85 for FWO and Starink methods are shown in Figs. 1 and 2 respectively. Table 3 presents the values of $E$ calculated from the individual slopes of the $\alpha$ ratio, the correlation factor and the relative difference between the two methods used. It was observed that the results for the $E$ obtained from both methods were in agreement with a difference of $<0.1 \%$. The relatively low difference between the methods might be due to the use of an iterative procedure in the evaluation of $E$ for FWO method as earlier mentioned in Section 2.4.1. The high value of $R^{2}$ between 0.15 and 0.65 conversion level revealed that

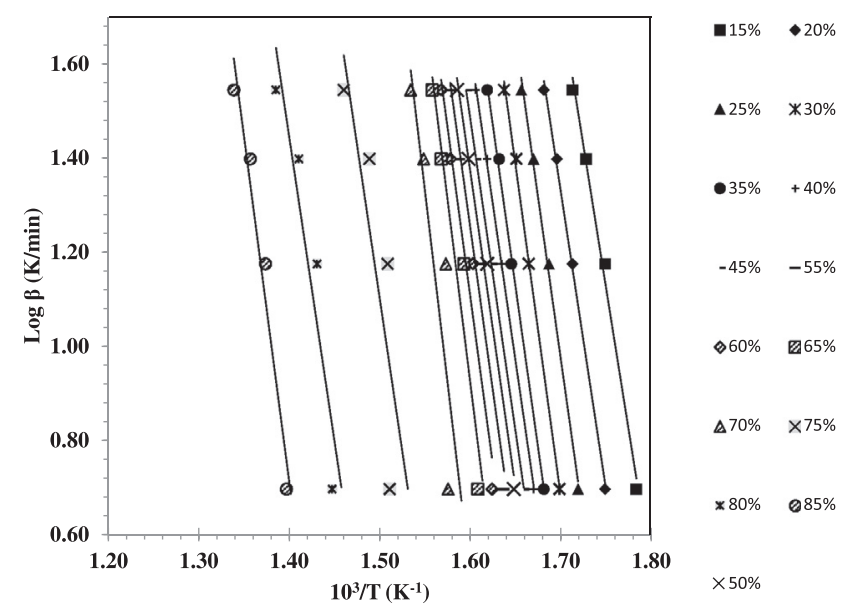

Fig. 1. Determination of $E$ according to Flynn Wall and Ozawa's (FWO) method at heating rates of $5,15,25$ and, $35 \mathrm{~K} / \mathrm{min}$. 


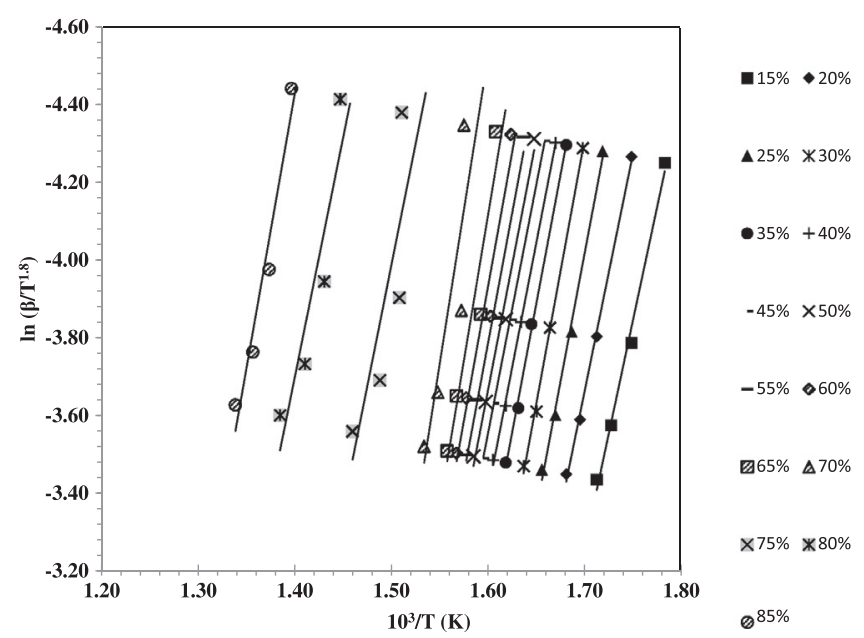

Fig. 2. Determination of $E$ according to Starink method at heating rates of 5, 15, 25 and, $35 \mathrm{~K} / \mathrm{min}$.

there was a strong correlation for the most part. Damartzis et al. (2011) recorded similarly high values of $R^{2}$ for levels between 0.20 and 0.80 in the application of iso-conversional methods for the kinetic study of Cynara cardunculus. The values at low conversion were not included in the calculation of the $E$ because of low correlation which can potentially introduce error in the data interpretation. At this stage of conversion it is mainly a physical reaction (drying process) that takes place and the current devolatilisation kinetic models are inadequate to define it accurately. Chen et al. (2013) made the same observation about the need to adopt a different model; moisture diffusion mechanism to obtain a better result for the drying stage.

For $\alpha$ between 0.15 and 0.60 , the $E$ hovers between 221 and $260 \mathrm{~kJ} / \mathrm{mol}$ and spikes to about $300 \mathrm{~kJ} / \mathrm{mol}$ at $\alpha$ level of 0.70 . Damartzis et al. (2011) observed a similar trend of variation in values of $E$ with increasing conversion. The variation in $E$ with increasing conversion may be attributed to biomass heterogeneity in which each polymeric fraction possesses a peculiar devolatilisation characteristic. The degree of polymerisation of the reacting pyrolysis compounds (secondary reactions), as the thermal decomposition progresses, could also influence variation in $E$. Hence, the devolatilisation kinetics can be accurately interpreted by a multi-step mechanism (Damartzis et al., 2011). As the reaction progresses, a dense carbon-rich structure (char) formed from either a cross-linking of polymer chains, polycondensation or cyclisation reaction of

Table 3

Activation energy for conversion range of $0.15-0.85$ using FWO and Starink methods.

\begin{tabular}{llllllr}
\hline $\begin{array}{l}\text { Conversion } \\
(\alpha)\end{array}$ & $\begin{array}{l}E \text { FWO } \\
\text { model } \\
(\mathrm{kJ} / \mathrm{mol})\end{array}$ & $R^{2}$ & $A\left(\mathrm{~min}^{-1}\right)$ & $\begin{array}{l}E \text { Starink } \\
\text { model } \\
(\mathrm{kJ} / \mathrm{mol})\end{array}$ & $R^{2}$ & \multicolumn{1}{l}{$\%$} \\
Difference & & \\
\hline 0.15 & 221.76 & 0.993 & $5.43 \times 10^{19}$ & 221.93 & 0.993 & -0.08 \\
0.20 & 232.61 & 0.998 & $2.01 \times 10^{20}$ & 232.51 & 0.993 & 0.04 \\
0.25 & 251.75 & 0.995 & $5.43 \times 10^{21}$ & 251.70 & 0.995 & 0.02 \\
0.30 & 259.15 & 0.998 & $1.85 \times 10^{22}$ & 259.07 & 0.997 & 0.03 \\
0.35 & 252.24 & 0.998 & $2.87 \times 10^{21}$ & 252.24 & 0.998 & 0.00 \\
0.40 & 244.13 & 0.999 & $4.39 \times 10^{20}$ & 244.05 & 0.999 & 0.03 \\
0.45 & 242.90 & 0.999 & $1.82 \times 10^{20}$ & 243.27 & 0.999 & -0.15 \\
0.50 & 246.87 & 0.989 & $5.89 \times 10^{20}$ & 246.77 & 0.988 & 0.04 \\
0.55 & 254.67 & 0.981 & $1.86 \times 10^{21}$ & 254.80 & 0.980 & -0.05 \\
0.60 & 263.18 & 0.955 & $1.65 \times 10^{22}$ & 263.01 & 0.952 & 0.06 \\
0.65 & 286.43 & 0.925 & $1.10 \times 10^{24}$ & 286.27 & 0.920 & 0.06 \\
0.70 & 300.58 & 0.758 & $9.55 \times 10^{24}$ & 300.37 & 0.746 & 0.07 \\
0.75 & 237.62 & 0.683 & $6.65 \times 10^{18}$ & 237.45 & 0.664 & 0.07 \\
0.80 & 235.56 & 0.875 & $9.60 \times 10^{17}$ & 235.35 & 0.865 & 0.09 \\
0.85 & 268.27 & 0.958 & $2.29 \times 10^{19}$ & 268.51 & 0.955 & -0.09 \\
\hline
\end{tabular}

Table 4

Analytical Py-GC/MS of teak showing retention time, molecular ion, compounds and\% peak area.

\begin{tabular}{|c|c|c|c|}
\hline $\begin{array}{l}\text { RT } \\
(\mathrm{min})\end{array}$ & $\begin{array}{l}\mathrm{M}^{+} \\
(m / z)\end{array}$ & Compound & $\begin{array}{l}\text { Peak area } \\
(\%)\end{array}$ \\
\hline 1.21 & 44 & Carbon dioxide & 10.4 \\
\hline 1.39 & $68,+72$ & Furan +2 -butanone & 5.7 \\
\hline 1.71 & 60 & Acetic acid & 6.4 \\
\hline 2.06 & 74 & 1-Hydroxy-2-propanone & 2.5 \\
\hline 3.17 & 104 & 1-Hydroxy-2-butanone + unknown & 2.5 \\
\hline 3.36 & 86 & Butanedial & 0.6 \\
\hline 3.47 & 102 & Methyl pyruvate & 1.2 \\
\hline 4.26 & 96 & Furfural & 1.3 \\
\hline 4.71 & 98 & Furfural alcohol & 0.4 \\
\hline 6.06 & 84 & 2(5)-Furanone & 0.7 \\
\hline 6.28 & 98 & 1,2-Cyclopentanedione & 1.6 \\
\hline 7.85 & 94 & Phenol & 0.1 \\
\hline 8.22 & 114 & $\mathrm{C}_{4} \mathrm{H}_{6} \mathrm{~N}_{2} \mathrm{O}$ & 1.1 \\
\hline 8.98 & 112 & 3-Methyl-1, 2-cyclopentanedione- & 2.1 \\
\hline 9.85 & 108 & 3-Methyl-phenol & 0.3 \\
\hline 10.43 & 108 & 4-Methyl-phenol & 0.2 \\
\hline 10.76 & 124 & Guaiacol & 1.4 \\
\hline 10.92 & 124 & 4-Methyl 1,2-benzenediol + unknown & 0.5 \\
\hline 11.62 & 126 & 3-Ethyl-2-hydroxy-2-cyclopenten-1-one & 0.1 \\
\hline 12.88 & 122 & 4-Ethyl-phenol & 0.1 \\
\hline 13.67 & 138 & Methyl guaiacol & 1.6 \\
\hline 14.17 & 144 & 1,4:3,6 Dianhydro-glucpyranose & 0.5 \\
\hline 14.46 & 144 & Di-anhydro-hexosan & 0.2 \\
\hline 14.48 & 120 & 4-Vinylphenol,-- & 0.2 \\
\hline 14.63 & 144 & Di-anhydro-hexosan & 0.4 \\
\hline 14.79 & 126 & 5-Hydroxymethyl-2-furancarboxaldehyde & 0.5 \\
\hline 15.61 & 140 & 3-Methoxy-1,2-benzenediol,- & 0.6 \\
\hline 16.03 & 152 & Ethyl-guaiacol & 0.4 \\
\hline 16.98 & 150 & 4-Vinylguaiacol & 2.0 \\
\hline 18.01 & 154 & Syringol & 0.8 \\
\hline 18.11 & 164 & Eugenol & 0.6 \\
\hline 19.25 & 152 & Vanillin & 1.2 \\
\hline 20.45 & 164 & Isoeugenol & 2.7 \\
\hline 20.72 & 166 & Propylguaiacol & 0.8 \\
\hline 21.13 & 162 & $\mathrm{C}_{10} \mathrm{H}_{12} \mathrm{O}_{2}$ & 0.3 \\
\hline 21.30 & 162 & $\mathrm{C}_{10} \mathrm{H}_{12} \mathrm{O}_{2}$ & 2.1 \\
\hline 21.37 & 166 & Acetoguaiacone & 2.1 \\
\hline 21.72 & 162 & Levoglucosan & 5.2 \\
\hline 22.62 & 162 & Anhydrohexosan & 0.6 \\
\hline 23.23 & 180 & 4-Vinyl-syringol & 1.1 \\
\hline 23.65 & 180 & Propioguaiacone & 0.4 \\
\hline 24.10 & 194 & 4-Allyl-syringol & 0.3 \\
\hline 25.42 & 182 & Syringaldehyde & 0.7 \\
\hline 25.64 & 180 & Cis-coniferyl alcohol & 0.5 \\
\hline 26.27 & 194 & 4-Propenyl-syringol & 0.9 \\
\hline 27.00 & $178+196$ & Coniferyl aldehyde + acetosyringone & 0.1 \\
\hline 27.08 & 180 & Trans-coniferyl alcohol & 4.6 \\
\hline 31.43 & 256 & Hexadecanoic acid & 0.3 \\
\hline 28.78 & 242 & $\mathrm{C}_{15} \mathrm{H}_{14} \mathrm{O}_{3}$ & 0.3 \\
\hline 34.23 & 222 & Methyl-anthroquinone & 0.5 \\
\hline 42.75 & 282 & Octadecenoic acid & 0.8 \\
\hline 47.35 & 282 & Octadecenoic acid & 0.8 \\
\hline 50.00 & 410 & Diplotene & 1.4 \\
\hline \multirow[t]{2}{*}{51.78} & 414 & Sitosterol & 0.4 \\
\hline & & Total unknown & 24.9 \\
\hline
\end{tabular}

side chains evolves (Lopez-Velazquez et al., 2013; Zhou et al., 2013). Its degradation evidently requires higher energy and this may have been responsible for the sudden rise in $E$. Kim et al. (2010) reported a similar finding in their kinetic study of pine trees. The $A$ varies linearly with the $E$. The least and highest values of $A$ are $9.60 \times 10^{17}$ and $9.55 \times 10^{24} \mathrm{~min}^{-1}$ at $\alpha$ of 0.8 and 0.7 respectively.

\subsection{Analytical pyrolysis (Py-GC/MS) of teak at $500{ }^{\circ} \mathrm{C}$}

During pyrolytic conversion processes of biomass, volatiles of diverse components are liberated from the breakdown of hemicellulose, cellulose and lignin fractions. Analytical Py-GC/MS 
technique is used to investigate the components that may be found in pyrolytic oil. Table 4 shows the retention time, molecular ion, and the \% peak area for the various compounds.

A total of 55 compounds were identified from the Py-GC/MS analysis of teak and about $75 \%$ were identified. The main compounds were $\mathrm{CO}_{2}(10.4 \%)$, acetic acid (6.4\%), furan +2 -butanone (5.7\%), levoglucosan (5.2\%), trans-coniferyl alcohol (4.6\%). Acetic acid and furfural, products of hemicellulose decomposition, were among the earliest compounds to emerge (Gao et al., 2013). It is well known that levoglucosan is an intermediate product primarily from cellulose decomposition. The formation of levoglucosan is from the rupture of glycosidic bonds and the rearrangement of glucose (Gaur and Reed, 1998; Gao et al., 2013). The proportion of phenolic organic compounds identified was more than one-third; however, the major ones are isoeugenol (2.7\%), acetoguaiacone (2.1\%), 4-vinylguaiacol (2.0\%), methyl guaiacol (1.6\%), guaiacol $(1.4 \%)$, and vanillin (1.2\%). These are from the deconstruction of lignin fraction and it is consistent with findings from literature (Pillai et al., 2011; Gao et al., 2013). The organic compound that emerged at the 50th minute is tentatively identified as diplotene.

\section{Conclusion}

Two different models were employed (Starink and FWO) to determine the kinetic data of teak wood and the results were comparable. The activation energy and the pre-exponential frequency factor varied between approximately 222 and $300 \mathrm{~kJ} / \mathrm{mol}$, and $9.6 \times 10^{17}$ and $9.55 \times 10^{24} \mathrm{~min}^{-1}$ as a function of conversion respectively. The presence of $\mathrm{CO}_{2}$, acetic acid, furan +2 -butanone, levoglucosan, and trans-coniferyl alcohol was detected in significant concentration by analytical Py-GC/MS technique. Furthermore, isoeugenol, acetoguaiacone, and 4-vinylguaiacol were the main phenolic organic compounds identified. Pyrolysed teak thus, serves as a good source of extraction of these chemical compounds.

\section{Acknowledgements}

We would like to acknowledge the technical help of Hui Li with the TGA.

\section{References}

Azeez, A.M., Meier, D., Odermatt, J., Willner, T., 2010. Fast pyrolysis of African and European lignocellulosic biomasses using Py-GC/MS and fluidized bed reactor. Energy Fuels 24, 2078-2085.

Babalola, F.D., 2008. Overhead wooden transmission pole (WTP) trade in Ibadan, Oyo state Nigeria: issues on product quality and standard. Obeche J. 26 (1), 12 22.

Biagini, E., Barontini, F., Tognotti, L., 2006. Devolatilization of biomass fuels and biomass components studied by TG/FTIR technique. Ind. Eng. Chem. Res. 45, 4486-4493.

Biagini, E., Fantei, A., Tognotti, L., 2008. Effect of the heating rate on the devolatilization of biomass residues. Thermochim. Acta 472, 55-63.

Bridgwater, A.V., 2003. Renewable fuels and chemicals by thermal processing of biomass. Chem. Eng. J. 91, 87-102.

Burhenne, L., Messmer, J., Aicher, T., Laborie, M., 2013. The effect of the biomass components lignin, cellulose and hemicellulose on TGA and fixed bed pyrolysis. J. Anal. Appl. Pyrol. 101, 177-184.

Cai, J.M., Bi, L.S., 2009. Kinetic analysis of wheat straw pyrolysis using isoconversional methods. J. Therm. AnaL. Calorim. 98, 325-330.
Chen, H., Liu, N., Fan, W., 2006. A new method to explain the model dependence of apparent activation energy derived from a single nonisothermal dynamic curve. Polym. Degrad. Stab. 91, 1726-1730.

Chen, D., Zheng, Y., Zhu, X., 2013. In-depth investigation on the pyrolysis kinetics of raw biomass. Part I: kinetic analysis for the drying and devolatilization stages. Bioresour. Technol. 131, 40-46.

Damartzis, T.H., Vamvuka, D., Sfakiotakis, S., Zabaniotou, A., 2011. Thermal degradation studies and kinetic modeling of cardoon (Cynara cardunculus) pyrolysis using thermogravimetric analysis (TGA). Bioresour. Technol. 102, 6230-6238.

Doyle, C.D., 1965. Series approximations to the equations of thermogravimetric data. Nature 207, 290-291.

Flynn, J.H., 1983. The iso-conversional method for determination of energy of activation at constant heating rates. J. Therm. Anal. 27, 95-102.

Gai, C., Dong, Y., Zhang, T., 2013. The kinetic analysis of the pyrolysis of agricultural residue under non-isothermal conditions. Bioresour. Technol. 127, 298-305.

Gao, N., Li, A., Quan, C., Du, L., Duan, Y., 2013. TG-FTIR and Py-GC/MS analysis on pyrolysis and combustion of pine sawdust. J. Anal. Appl. Pyrol. 100, 26-32.

Gaur, S., Reed, T.B., 1998. Thermal Data for Natural Synthetic Fuels. Marcel Dekker, New York.

Greenhalf, C.E., Nowakowski, D.J., Harms, A.B., Titiloye, J.O., Bridgwater, A.V., 2013. A comparative study of straw, perennial grasses and hardwoods in terms of fast pyrolysis products. Fuel 108, 216-230.

Kim, S., Kim, J., Park, Y., Park, Y., 2010. Pyrolysis kinetics and decomposition characteristics of pine trees. Bioresour. Technol. 101, 9797-9802.

Lasode, O.A., Balogun, A.O., 2010. Wood wastes generation in Ilorin metropolis: problems, management and prospects. In: Proceedings of the 25th International Conference on Solid Waste Technology and Management, Philadelphia, PA U.S.A.

Lopez-Velazquez, M.A., Santes, V., Balmaseda, J., Torres-Garcia, E., 2013. Pyrolysis of orange waste: a thermo-kinetic study. J. Anal. Appl. Pyrol. 99, 170-177.

Oloyede, I., Ayorinde, K.L., Oladele, F.A., 2009. Greening the campus environment: The University of Ilorin Experience. 12th General Conference. Association of African Universities, Abuja, Nigeria.

Pillai, K.V., McDonald, A.G., Wagner, F.G., 2011. Developing a model system in vitro to understand tracheary element development in Douglas-fir (Pseudotuga mensziesii). Maderas Ciencia y tecnología 13 (1), 3-18.

Prins, M.J., Ptasinski, K.J., Janssen, F.J.J.G., 2006. Torrefaction of wood part 1: weight loss kinetics. J. Anal. Appl. Pyrol. 77 (1), 28-34.

Sami, M., Annamalai, K., Woodridge, M., 2001. Co-firing of coal and biomass fuel blends. Prog. Energy Combust. Sci. 27, 171-214.

American Standard of Testing and Materials, 2004. ASTM D5865-04, 2004. Standard Test Method for Gross Calorific Value of Coal and Coke. ASTM International, West Conshohocken, PA.

American Standard of Testing and Materials, 1984. ASTM D1102-84, 2007. Standard Test Method for Ash in Wood. ASTM International, West Conshohocken, PA.

American Standard of Testing and Materials, 1996. ASTM D1106-96, 2007. Standard Test Method for Acid-insoluble Lignin in Wood. ASTM International, West Conshohocken, PA.

American Standard of Testing and Materials, 1996. ASTM D1108-96, 2007. Standard Test Method for Dichloromethane (DCM) Solubles in Wood. ASTM International, West Conshohocken, PA.

American Standard of Testing and Materials, 2001. ASTM E1641-07, 2007. Standard Test Method for Decomposition Kinetics by Thermogravimetry. ASTM International, West Conshohocken, PA.

Starink, M.J., 1996. A new method for the derivation of activation energies from experiments performed at constant heating rate. Thermochim. Acta 288, 97 104.

Telmo, C., Lousada, J., 2011. The explained variation by lignin and extractive contents on higher heating value of wood. Biomass Bioenerg. 35, 1663-1667.

White, J.E., Catallo, W.J., 2011. Biomass pyrolysis kinetics: a comparative critica review with relevant agricultural residue case studies. J. Anal. Appl. Pyrol. 91 (1), 1-33.

Wilson, L., Yang, W., Blasiak, W., John, G.R., Mhilu, C.F., 2011. Thermal characterization of tropical biomass feedstocks. Energy Convers. Manage. 52 191-198.

Wongsiriamnuay, T., Tippayawong, N., 2010. Non-isothermal pyrolysis characteristics of giant sensitive plants using thermogravimetric analysis Bioresour. Technol. 101, 5638-5644.

Zhou, D., Grant, D.J.W., 2004. Model dependence of the activation energy derived from nonisothermal kinetic data. J. Phys. Chem. 108, 4239-4246.

Zhou, S., Garcia-Perez, M., Pecha, B., McDonald, A.G., Kersten, S., Westerhof, R., 2013. Secondary vapor phase reactions of lignin derived oligomers obtained by the fast pyrolysis of pine wood. Energy Fuels 27, 1428-1438. 